\title{
DETEKSI GANGGUAN AUTIS PADA ANAK MENGGUNAKAN METODE MODIFIED K-NEAREST NEIGHBOR
}

\author{
Yuliasih Kripsiandita ${ }^{1}$, Deni Arifianto $^{2}$, Qurrota A'yun ${ }^{3}$ \\ Program Studi Teknik informatika, Fakultas Teknik, Universitas Muhammadiyah Jember \\ yuliasihkripsiandita@gmail.com ${ }^{1}$, deniarifianto@unmuhiember.ac.id ${ }^{2}$, \\ qurrota.ayun@unmuhiember.ac.id ${ }^{3}$
}

(Naskah masuk: 25 Februari 2021, diterima untuk diterbitkan: 26 April 2021)

\begin{abstract}
ABSTRAK
Autism Spectrume Disorder merupakan ganggguan perkembanan dimana seorang anak memperlihatkan suatu perilaku menjauhkan diri dari lingkungan sosialnya, seakan - akan hidup di dunianya sendiri. Semakin dini mengetahui anak menderita gangguan autis sangatlah penting, karena semakin dini autis diobati semakin besar peluang untuk sembuh. Dengan adanya perkembangan teknologi pendeteksian gejala autis dapat dilakukan lebih awal menggunakan sistem deteksi autis berbasis web. Metode Modified K-Nearest Neighbor merupakan perkembangan dari metode konvensional K-Nearest Neighbor. Deteksi autis pada anak menggunakan metode Modified K-Nearest Neighbor dengan data yang digunakan diambil dari website UCI Machine Learning Repository, dengan jumlah data 292 data dan 2 class output. Pengujian dilakukan dengan mencari kedekatan dari data training dan data testing untuk menghitung Weight voting, setelah mendapatkan hasil weight voting akan dicari mayoritas datanya. Berdasarkan pengujian yang telah dilakukan didapatkan hasil akurasi tertinggi sebesar $96,67 \%$, hasil presisi tertinggi sebesar $97,33 \%$ dan hasil recall tertinggi sebesar $100 \%$ pada $K=13$. Untuk $K$ optimal dari pengujian ini ditunjukkan pada $\mathrm{K}=3$.
\end{abstract}

Kata Kunci : Deteksi Autisme, Klasifikasi, Metode Modified K-Nearest Neighbor

\begin{abstract}
Autism Spectrume Disorder is a development disturbance in which a child shows a behavior of distancing himself from his social environment, as though living in his own world. The earlier it is known that a child has an autistic disorder is very important, because the earlier autism is treated, the greater the chance of recovery. With the use of technological developments, autism symptom detection can be done earlier using a web-based autism detection system.Modified K-Nearest Neighbor method is a development of the conventional K-Nearest Neighbor method. Autism detection in children uses the Modified K-Nearest Neighbor method with the data used taken from the UCI Machine Learning Repository website, with a total of 292 data and 2 output classes. Testing is done by looking for the closeness of each training data to determine the validity value, after that look for the closeness of training data and testing data to calculate weight voting, after getting the results of weight voting the majority of the data will be searched. Based on the results of the test which have been done, it was found out that the highest accuracy results were $96.67 \%$,
\end{abstract}


highest precision results were $97,33 \%$ and highest recall results were $100 \%$ at $K=13$. For the optimal $k$ of this test was shown at $K=3$.

Keywords: Autism Detection, Classification, Modified K-Nearest Neighbor Method.

\section{PENDAHULUAN}

Autisme merupakan salah satu gangguan tumbuh kembang yang menyebabkan fungsi otak tidak bekerja secara normal sehingga dapat berpengaruh pada kemampuan berkomunikasi dan berinteraksi sosial seseorang. Gejala pada autisme dapat diketahui dari adanya penyimpangan tumbuh kembang seorang anak (Sunu, 2012). Kurangnya pengetahuan pada gejala awal autisme menyebabkan peningkatan jumlah penderitanya.

Untuk mengurangi kesalahan dalam deteksi dan mengurangi keterlambatan dalam diagnosa maka dibutuhkan sebuah sistem yang mampu mendeteksi gejala autis sejak dini dengan menggunakan penerapan teknik data mining metode klasifikasi. Metode klasifikasi dapat dilakukan dengan memetakan suatu item data ke dalam kelas berdasarkan kelas data yang telah didefinisikan sebelumnya (Agarwal, 2014).

Aplikasi berbasis web merupakan suatu aplikasi, yang dapat diakses melalui penjelajah web menggunakan jaringan seperti internet. Aplikasi web menjadi populer karena kemudahan dalam mengaksesnya. Jadi pada penelitian ini akan dibuat deteksi autis berbasis web, agar memudah orangtua untuk mengetahui lebih awal gejala autis pada anak.

Metode Modified K-Nearest Neighbor merupakan pengembangan dari metode konvensional K-Nearest Neighbor. Dimana dilakukan modifikasi dengan menambahkan proses validitas dan proses weight voting (Parvin et al., 2010).
Sebagai pendukung proses olah data penulis memutuskan menggunakan metode Modified K-Nearest Neighbor. Karena pada penelitian sebelumnya dengan judul "Modified K-Nearest Neighbor untuk Prediksi Curah Hujan" yang dilakukan oleh (Muhammad, 2015) didapatkan hasil nilai akurasi terbaik sebesar $82,46 \%$. Pada penelitian selanjutnya dengan judul "Deteksi Penyakit Kucing dengan menggunakan Modified K-Nearest Neighbor Teroptimasi" yang dilakukan oleh (Fitri et al., 2017) didapatkan hasil untuk $\mathrm{K}$ optimal 1 sebesar $100 \%$ menggunakan algoritma genetika. Dan pada penelitian selanjutnya dengan judul "Klasifikasi Kelompok Varietas Unggul padi menggunakan Modified $K$ Nearest Neighbor" didapatkan hasil akurasi tertinggi sebesar $79,96 \%$ dan nilai akurasi terendah 51,2\%. Melihat hasil dari penelitian - penetian sebelumnya diharapkan pada penelitian ini mampu menghasilkan nilai akurasi yang lebih baik.

Berdasarkan paparan yang telah dikemukakan diatas, penulis tertarik untuk mengimplentasikan deteksi dini autis melalui penelitian dengan juduk "Deteksi Gangguan Autis pada Anak menggunakan metode Modified K-Neraest Neighbor" . jawaban dari setiap pertanyaan pada screening kemudian dijadikan bahan msukan untuk menklasifikasi autis. Penggunakan metode Modified K-Nearest Neighbor diharapkan dapat memberikan hasil nailai akurasi, presisi dan recall yang tinggi. 


\section{METODOLOGI PENELITIAN}

\subsection{Data Penelitian}

Pada data penelitian ini data yang digunakan merupakan data sekunder yang diperoleh dari media internet pada website $\mathrm{UCl}$ Machne Learning (https://archive.ics.uci.edu/ml/index.php) tentang Autism Spectrume Disorder dari Auckland New Zeland pada tahun 2017 dengan jumlah data 150 dan 10 atribute

\subsection{Metode K-Nearest Neighbor} Metode K-Nearest Neighbor merupakan metode yang paling dasar dari contoh based learning dan juga termasuk kelompok instance-based learning. K-dalam penelitian. Nearest Neighbor dilakukan dengan mencari kelompok objek dalam data training yang paling dekat dengan dengan objek pada data testing (Saxena et al., 2014). Metode KNN dapat dihitung menggunakan persamaan Euclidean Distance.

Euclidean Distance merupakan perhitungan jarak dari dua titik dalam Euclidean Space, untuk mempelajari hubungan antar dua jarak (Nurliza, 2018). Berikut ini rumus dari Euclidean Distance yang digunakan untuk menghitung jarak antar titik pada data training $(x)$ dan titik pada data testing $(y)$ :

$d(x, y)=\sqrt{\sum_{i=1}^{n}\left(x_{i}-y_{i}\right)^{2}}$

Keterangan:

$d(x, y)$ : jarak Euclidean

$x i \quad$ : data training ke- $i$

$y i \quad$ : data testing ke- $i$

$i \quad: 1,2,3, \ldots, \mathrm{n}$

\subsection{Metode Modified K-Nearest Neighbor Metode Modified K-Nearest} Neighbor merupakan suatu pengembangan dari metode $K$-Nearest Neighbor yang diusulkan oleh (Parvin et al., 2010) yang sebagian bertujuan untuk perubahan pada tingkat akurasi yang rendah pada metode
K-Nearest Neighbor. Pengembangan dilakukan dengan memodifikasi metode $K$ Nearest Neighbor yang bertujuan untuk meningkatkan kinerja dan akurasi pada metode K-Nearest Neighbor. Pada metode Modified K-Nearest Neighbor terdapat penambahan proses yakni proses validitas data pada setiap dataset yang telah dilakukan perhitungan jarak euclidean antar data training. Dan juga penambahan proses weight voting yang didapatkan dari hasil nilai validitas data dikalikan dengan hasil perhitungan jarak euclidean data training dan data testing (Parvin et al., 2010).

\section{a. Perhitungan Nilai Validitas}

Dalam metode Modified K-Nearest Neighbor suatu data akan melalui tahap validitas setelah mendapatkan hasil dari perhitungan jarak euclidean atar data training (Parvin et al., 2010). Untuk perhitungan nilai validitas digunakan persamaan sebagai berikut:

$\operatorname{Validity}(i)=\frac{1}{H} \sum_{i=1}^{H} S(\operatorname{lbl}(x), \operatorname{lbl}(N i(x)))$

Keterangan :

$H \quad$ : nilai tetangga yang digunakan

$\operatorname{lbl}(x)$ : label dari dataset

$N i(x)$ : label dari tetangga terdekat dengan $x$

$i \quad: 1,2,3 \ldots . \mathrm{H}$.

$S \quad$ : Fungsi yang memperhitungkan kesamaan antara satu dataset dengan dataset yang lain.

Berikut definisi dari fungsi $S$ :

$S(a, b)=\left\{\begin{array}{lll}1 & j i k a & a=b \\ 0 & j i k a & a \neq b\end{array}\right.$

Keterangan :

a : Kelas a pada data latih

$b \quad$ : kelas lain selain $a$ pada data latih

b. Perhitungan Weight Voting

Weight Voting datset dalam metode Modified K-Nearest Neighbor merupakan 
salah satu dari modifikasi yang dilakukan pada metode konvensional K-Nearest Neighbor. Dimana dilakukan penentuan kelas dari data objek yang baru dengan cara melakukan pemilihan berdasarkan bobot pada dataset. Setiap datasetakan diberikan bobot dengan melakukan perhitungan dengan persamaan seperti dibawah ini (Parvin et al., 2010) :

$W(i)=\operatorname{Validity}(i) \times \frac{1}{d e+a}$

Keterangan :

$W(i) \quad$ : Bobot

Validity $(i)$ : Validitas dari $i$ tetangga terdekat antara dataset dan data uji

de : Jarak Euclidean antar data latih dengan data uji

: Konstanta

Teknik weight voting akan memberikan nilai yang tinggi pada dataset yang memilki nilai validitas yang besar serta kesamaan yang tinggi dengan data testing (Parvin et al., 2010)

\section{HASIL DAN PEMBAHASAN}

\subsection{Implementasi}

Bagian ini menjelaskan mengenai implementasi mengenai antarmuka yang terdiri dari implementasi halaman beranda, halaman deteksi autis dan halaman testing (proses pengujian metode MKNN).

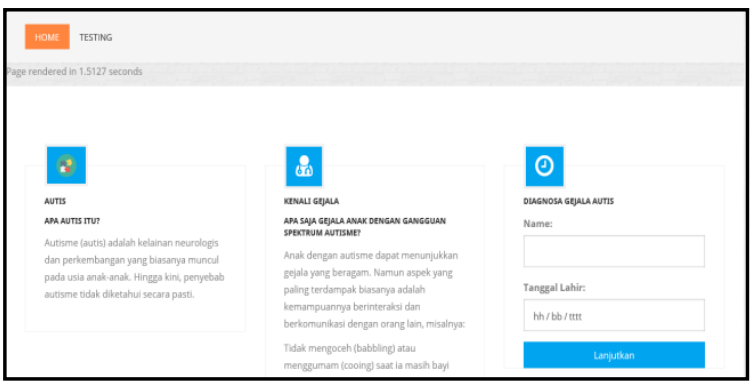

Gambar 3. 1 Tampilan Halaman Beranda

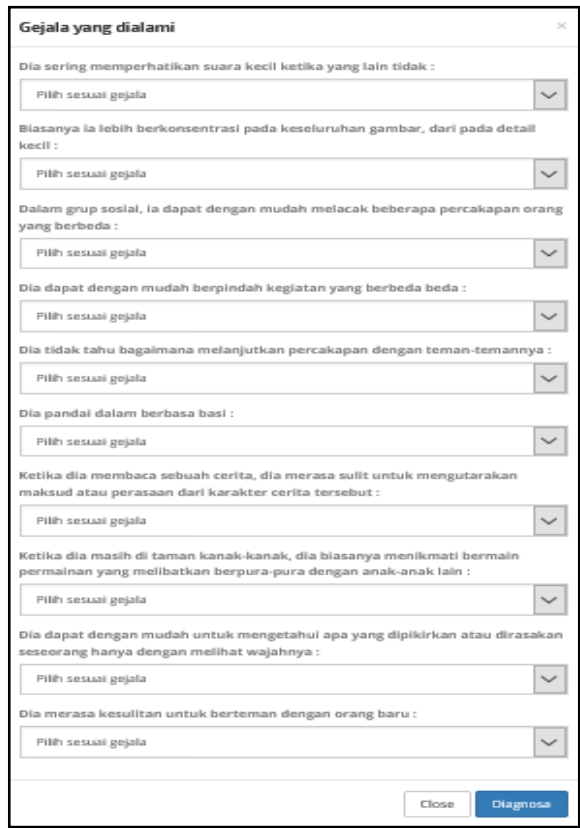

Gambar 3. 2 Tampilan halaman Deteksi Autis

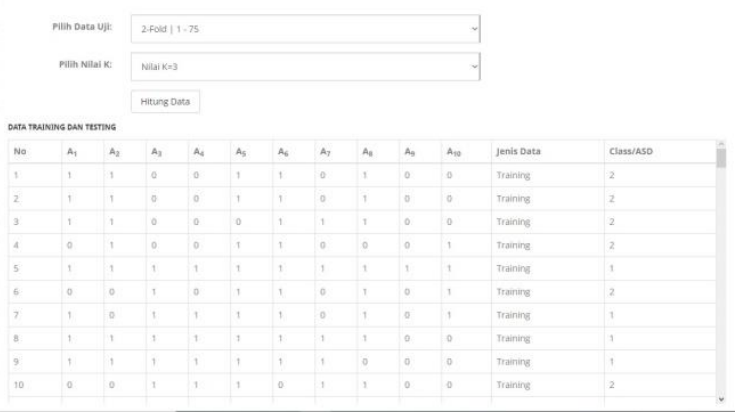

Gambar 3. 3 Tampilan Halaman Testing

Setelah dilakukan pengujian pada halaman testing didapatkan hasil akurasi, presisi dan recall seperti pada tabel dibawah ini :

\subsection{Pengujian $K$-fold}

Pengujian K-fold dilakukan menggunakan 2-fold, 3 fold dan 5-fold dengan jumlah data 150 data. Setelah dilakukan pengujian didapatkan hasil akurasi, presisi dan recall yang ditunjukkan pada tabel dibawah ini . 
Tabel 3. 1 Hasil Akurasi, Presisi dan Recall Pada 2-fold Skenario 1

\begin{tabular}{|c|c|c|c|}
\hline Nilai K & \multicolumn{3}{|c|}{ 2-Fold Skenario 1 } \\
\hline & Akurasi & Presisi & Recall \\
\hline 3 & $86,67 \%$ & $86,67 \%$ & $76,92 \%$ \\
\hline 5 & $81,33 \%$ & $81,33 \%$ & $68,89 \%$ \\
\hline 7 & $77,33 \%$ & $77,33 \%$ & $64,58 \%$ \\
\hline 9 & $72 \%$ & $72 \%$ & $59,62 \%$ \\
\hline 11 & $60 \%$ & $60 \%$ & $50,82 \%$ \\
\hline 13 & $60 \%$ & $49,33 \%$ & $44,93 \%$ \\
\hline
\end{tabular}

Tabel 3.1 menunjukan hasil dari pengujian dengan 2-fold skenario 1, didapatkan hasil akurasi tertinggi sebesar $86,67 \%$, presisi tertinggi $86,67 \%$ dan recall tertinggi $76,92 \%$ yang terdapat pada $\mathrm{K}=3$.

Tabel 3. 2 Hasil Akurasi, Presisi dan Recall pada 2-fold Skenario 2

\begin{tabular}{|c|c|c|c|}
\hline Nilai K & \multicolumn{3}{|c|}{ 2-Fold Skenario 2 } \\
\hline & Akurasi & Presisi & Recall \\
\hline 3 & $91,89 \%$ & $86,96 \%$ & $100 \%$ \\
\hline 5 & $90,54 \%$ & $90,24 \%$ & $92,50 \%$ \\
\hline 7 & $87,84 \%$ & $82,98 \%$ & $97,50 \%$ \\
\hline 9 & $75,68 \%$ & $68,97 \%$ & $100 \%$ \\
\hline 11 & $74,32 \%$ & $67,80 \%$ & $100 \%$ \\
\hline 13 & $75,68 \%$ & $68,97 \%$ & $100 \%$ \\
\hline
\end{tabular}

Tabel 3.2 menunjukan hasil dari pengujian dengan 2-fold skenario 2, didapatkan hasil akurasi tertinggi sebesar $91,89 \%$, presisi tertinggi $90,24 \%$ dan recall tertinggi $100 \%$.

Tabel 3. 3 Hasil Akurasi, Presisi dan Recall Pada 3-fold Skenario 1

\begin{tabular}{|c|c|c|c|}
\hline Nilai K & \multicolumn{3}{|c|}{ 3-Fold Skenario 1 } \\
\hline & Akurasi & Presisi & Recall \\
\hline 3 & $90 \%$ & $80,77 \%$ & $100 \%$ \\
\hline 5 & $88 \%$ & $77,88 \%$ & $100 \%$ \\
\hline 7 & $88 \%$ & $77,78 \%$ & $100 \%$ \\
\hline 9 & $86 \%$ & $75 \%$ & $100 \%$ \\
\hline 11 & $90 \%$ & $83,33 \%$ & $95,24 \%$ \\
\hline 13 & $88 \%$ & $77,78 \%$ & $100 \%$ \\
\hline
\end{tabular}

Tabel 3.3 menunjukan hasil dari pengujian dengan 3 -fold skenario 1 , didapatkan hasil akurasi tertinggi sebesar
$90 \%$, presisi tertinggi $83,33 \%$ dan recall tertinggi $100 \%$.

Tabel 3. 4 Hasil Akurasi, Presisi dan Recall Pada 3-fold Skenario 2

\begin{tabular}{|c|c|c|c|}
\hline Nilai K & \multicolumn{3}{|c|}{ 3-Fold Skenario 2 } \\
\hline & Akurasi & Presisi & Recall \\
\hline 3 & $92 \%$ & $86,67 \%$ & $100 \%$ \\
\hline 5 & $90 \%$ & $86,21 \%$ & $96,15 \%$ \\
\hline 7 & $90 \%$ & $83,87 \%$ & $100 \%$ \\
\hline 9 & $86 \%$ & $78,79 \%$ & $100 \%$ \\
\hline 11 & $80 \%$ & $72,22 \%$ & $100 \%$ \\
\hline 13 & $78 \%$ & $70,27 \%$ & $100 \%$ \\
\hline
\end{tabular}

Tabel 3.4 menunjukan hasil dari pengujian dengan 3-fold skenario 2, didapatkan hasil akurasi tertinggi sebesar $90 \%$, presisi tertinggi $86,67 \%$ dan recall tertinggi $100 \%$.

Tabel 3. 5 Hasil Akurasi, Presisi dan Recall Pada 3-fold Skenario 3

\begin{tabular}{|c|c|c|c|}
\hline Nilai K & \multicolumn{3}{|c|}{ 3-Fold Skenario 3 } \\
\hline & Akurasi & Presisi & Recall \\
\hline 3 & $87,76 \%$ & $80 \%$ & $100 \%$ \\
\hline 5 & $85,71 \%$ & $77,42 \%$ & $100 \%$ \\
\hline 7 & $75,51 \%$ & $66,67 \%$ & $100 \%$ \\
\hline 9 & $71,43 \%$ & $63,16 \%$ & $100 \%$ \\
\hline 11 & $71,43 \%$ & $63,16 \%$ & $100 \%$ \\
\hline 13 & $69,39 \%$ & $61,54 \%$ & $100 \%$ \\
\hline
\end{tabular}

Tabel 3.5 menunjukan hasil dari pengujian dengan 3-fold skenario 3, didapatkan hasil akurasi tertinggi sebesar $87,76 \%$, presisi tertinggi $80 \%$ dan recall tertinggi $100 \%$.

Tabel 3. 6 Hasil Akurasi, Presisi dan Recall Pada 5-fold Skenario 1

\begin{tabular}{|c|c|c|c|}
\hline Nilai K & \multicolumn{3}{|c|}{ 5-Fold Skenario 1 } \\
\hline & Akurasi & Rresisi & Recall \\
\hline 3 & $86,67 \%$ & $78,95 \%$ & $100 \%$ \\
\hline 5 & $90 \%$ & $83,33 \%$ & $100 \%$ \\
\hline 7 & $90 \%$ & $83,33 \%$ & $100 \%$ \\
\hline 9 & $90 \%$ & $83,33 \%$ & $100 \%$ \\
\hline 11 & $93,33 \%$ & $88,24 \%$ & $100 \%$ \\
\hline 13 & $96,67 \%$ & $97,33 \%$ & $100 \%$ \\
\hline
\end{tabular}

Tabel 3.6 menunjukan hasil dari pengujian dengan 5 -fold skenario 1 , 
didapatkan hasil akurasi tertinggi sebesar $96,67 \%$, presisi tertinggi $97,33 \%$ dan recall tertinggi $100 \%$.

Tabel 3. 7 Hasil Akurasi, Presisi dan Recall Pada 5-fold Skenario 2

\begin{tabular}{|c|c|c|c|}
\hline Nilai K & \multicolumn{3}{|c|}{ 5-Fold Skenario 2 } \\
\hline & Akurasi & Rresisi & Recall \\
\hline 3 & $83,33 \%$ & $66,67 \%$ & $100 \%$ \\
\hline 5 & $76,67 \%$ & $60 \%$ & $90 \%$ \\
\hline 7 & $76,67 \%$ & $60 \%$ & $90 \%$ \\
\hline 9 & $76,67 \%$ & $60 \%$ & $90 \%$ \\
\hline 11 & $76,67 \%$ & $58,82 \%$ & $90 \%$ \\
\hline 13 & $80 \%$ & $62,50 \%$ & $100 \%$ \\
\hline
\end{tabular}

Tabel 3.7 menunjukan hasil dari pengujian dengan 5-fold skenario 2, didapatkan hasil akurasi tertinggi sebesar $83,33 \%$, presisi tertinggi $66,67 \%$ dan recall tertinggi $100 \%$.

Tabel 3. 8 Hasil Akurasi, Presisi dan Recall Pada 5-fold Skenario 3

\begin{tabular}{|c|c|c|c|}
\hline Nilai K & \multicolumn{3}{|c|}{ 5-Fold Skenario 3 } \\
\hline & Akurasi & Rresisi & Recall \\
\hline 3 & $90 \%$ & $83.33 \%$ & $100 \%$ \\
\hline 5 & $86,67 \%$ & $78,95 \%$ & $100 \%$ \\
\hline 7 & $80 \%$ & $71,43 \%$ & $100 \%$ \\
\hline 9 & $80 \%$ & $71,43 \%$ & $100 \%$ \\
\hline 11 & $76,67 \%$ & $68,18 \%$ & $100 \%$ \\
\hline 13 & $80 \%$ & $71,43 \%$ & $100 \%$ \\
\hline
\end{tabular}

Tabel 3.8 menunjukan hasil dari pengujian dengan 5-fold skenario 3, didapatkan hasil akurasi tertinggi sebesar $86,67 \%$, presisi tertinggi $83,33 \%$ dan recall tertinggi $100 \%$.

Tabel 3. 9 Hasil Akurasi, Presisi dan Recall Pada 5-fold Skenario 4

\begin{tabular}{|c|c|c|c|}
\hline Nilai K & \multicolumn{3}{|c|}{ 5-Fold Skenario 4 } \\
\hline & Akurasi & Rresisi & Recall \\
\hline 3 & $90 \%$ & $93,33 \%$ & $87,50 \%$ \\
\hline 5 & $96,67 \%$ & $94,12 \%$ & $100 \%$ \\
\hline 7 & $93,33 \%$ & $88,89 \%$ & $100 \%$ \\
\hline 9 & $80 \% \%$ & $72,73 \%$ & $100 \%$ \\
\hline 11 & $80 \%$ & $72,73 \%$ & $100 \%$ \\
\hline 13 & $80 \%$ & $72,73 \%$ & $100 \%$ \\
\hline
\end{tabular}

Tabel 3.9 menunjukan hasil dari pengujian dengan 5-fold skenario 4, didapatkan hasil akurasi tertinggi sebesar $96,67 \%$, presisi tertinggi $94,12 \%$ dan recall tertinggi $100 \%$.

Tabel 3. 10 Hasil Akurasi, Presisi dan Recall Pada 5-fold Skenario 5

\begin{tabular}{|c|c|c|c|}
\hline Nilai K & \multicolumn{3}{|c|}{5 -Fold Skenario 5 } \\
\hline & Akurasi & Rresisi & Recall \\
\hline 3 & $86,21 \%$ & $86,21 \%$ & $100 \%$ \\
\hline 5 & $89,66 \%$ & $83,33 \%$ & $100 \%$ \\
\hline 7 & $79,31 \%$ & $71,43 \%$ & $100 \%$ \\
\hline 9 & $72,41 \%$ & $65,22 \%$ & $100 \%$ \\
\hline 11 & $72,41 \%$ & $65,22 \%$ & $100 \%$ \\
\hline 13 & $68,97 \%$ & $62,5 \%$ & $100 \%$ \\
\hline
\end{tabular}

Tabel 3.10 menunjukan hasil dari pengujian dengan 5-fold skenario 5, didapatkan hasil akurasi tertinggi sebesar $89,66 \%$, presisi tertinggi $86,21 \%$ dan recall tertinggi $100 \%$.

\subsection{Pengujian Pengaruh Nilai K}

Pengujian terhadap nilai $K$ dilakukan menggunakan nilai $K$ yang bervariasi, yakni nilai $\mathrm{K}=3, \mathrm{~K}=5, \mathrm{~K}=7, \mathrm{~K}$ $=9, \mathrm{~K}=11$ dan $\mathrm{K}=13$ dengan jumlah data latih yang berbeda yaitu 75,100 , dan 120 data latih. Pengujian nilai $\mathrm{K}$ dilakukan dengan masing - masing data latih lalu dilakukan analisa terhadap nilai rata - rata yang didapatkan dari pengujian. Hasil pengujian pengaruh nilai $\mathrm{K}$ terhadap akurasi ditunjukan pada tabel dibawah ini.

Tabel 3. 11 Hasil Pengujian Pengaruh Nilai K

\begin{tabular}{|c|c|c|c|c|}
\hline $\begin{array}{c}\text { NILAI } \\
\mathrm{K}\end{array}$ & $\begin{array}{c}75 \text { data } \\
\text { latih }\end{array}$ & $\begin{array}{c}100 \\
\text { Data } \\
\text { latih }\end{array}$ & $\begin{array}{c}120 \\
\text { Data } \\
\text { Latih }\end{array}$ & $\begin{array}{c}\text { Rata }- \\
\text { rata } \\
\text { Akurasi }\end{array}$ \\
\hline 3 & $86,67 \%$ & $90 \%$ & $86,67 \%$ & $87.78 \%$ \\
\hline 5 & $81,33 \%$ & $88 \%$ & $90 \%$ & $86.44 \%$ \\
\hline 7 & $77,33 \%$ & $88 \%$ & $90 \%$ & $85.11 \%$ \\
\hline 9 & $72 \%$ & $86 \%$ & $90 \%$ & $82.67 \%$ \\
\hline 11 & $60 \%$ & $90 \%$ & $93,33 \%$ & $81,11 \%$ \\
\hline 13 & $60 \%$ & $88 \%$ & $96,67 \%$ & $81,56 \%$ \\
\hline
\end{tabular}


Dari pengujian pengaruh nilai $\mathrm{K}$ yang telah dilakukan didapatkan hasil dari nilai $\mathrm{K}=3$ menunjukan rata - rata akurasi dengan presentase $87,78 \%$. Untuk nilai $\mathrm{K}=5$ menunjukan rata rata akurasi dengan nilai presentase $86,44 \%$. Untuk nilai $\mathrm{K}=7$ menunjukan rata - rata akurasi dengan presentase $85,11 \%$. Untuk nilai $\mathrm{K}=9$ menunjukan rata - rata akurasi dengan presentase $82,67 \%$. Untuk nilai $\mathrm{K}=11$ menunjukan rata - rata akurasi dengan presentase $81,11 \%$. Dan untuk nilai $\mathrm{K}=13$ menunjukan rata - rata akurasi dengan presentase $81,56 \%$. Grafik hasil pengujian pengaruh nilai $\mathrm{K}$ terhadap akurasi ditunjukan pada Gambar 3.4

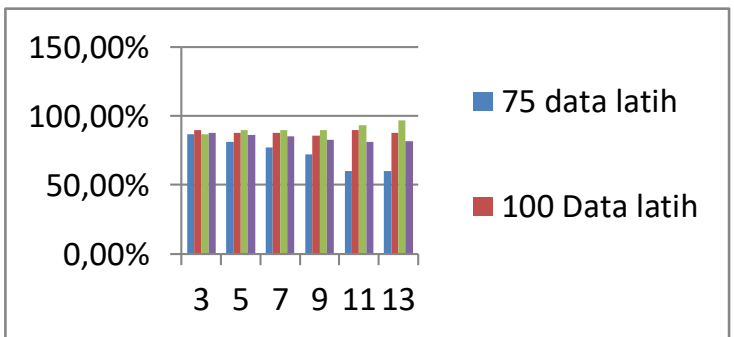

Gambar 3. 4 Grafik Pengujian Pengaruh Nilai $\mathrm{K}$

\section{KESIMPULAN}

Kesimpulan yang dapat diambil dari penelitian ini yaitu nilai akurasi tertinggi sebesar $96,67 \%$, nilai presisi tertinggi sebesar $97,33 \%$ dan nilai recall tertinggi sebesar $100 \%$ pada $K=11$ dengan jumlah data latih 120 data. Untuk rata - rata akurasi tertinggi sebesar $87,78 \%$ terdapat pada $\mathrm{K}=3$.

Saran yang dapat diberikan untuk penelitian selanjutnya dapat menggunakan nilai $\mathrm{K}$ dan $\mathrm{K}$-fold yang lebih beragam dan bisa mengembangkan sistem deteksi autis pada anak dengan penelitian ini sebagai acuan.

\section{DAFTAR PUSTAKA}

Agarwal, S. (2014). Data mining: Data mining concepts and techniques. Proceedings -
2013 International Conference on Machine Intelligence Research and Advancement, ICMIRA 2013. https://doi.org/10.1109/ICMIRA.2013.45

Fitri, A. D., Eka, R. D., \& Wahyu, W. A. (2017). Deteksi Penyakit Kucing dengan Menggunakan Modified K-Nearest Neighbor Teroptimasi ( Studi Kasus: Puskeswan Klinik Hewan dan Satwa Sehat Kota Kediri ). Jurnal Pengembangan Teknologi Informasi dan IImu Komputer (J-PTIIK) Universitas Brawijaya, 1(11), 1295-1301.

Muhammad, B. L. (2015). Modified Nearest Neighbor Untuk Prediksi Curah Hujan. Konferensi Nasional Sistem dan Informatika 2015, 1, 272-277. http://ejournal.stikombali.ac.id/index.php/knsi/article/view/463/1 15

Nurliza, N. N. (2018). Penerapan Euclidean Distance Pada Pengenalan Pola Citra Sidik Jari. 1-67.

Parvin, H., Alizadeh, H., \& Minati, B. (2010). A Modification on K-Nearest Neighbor Classifier. Global Journal of Computer Science and Technology, 10(14), 37-41.

Saxena, K., Khan, Z., \& Singh, S. (2014). Diagnosis of Diabetes Mellitus using $K$ Nearest Neighbor Algorithm. International Journal of Computer Science Trends and Technology (IJCST).

Sunu, C. (2012). Panduan memecahkan masalah autism unlocking autism. Lintangterbit. 